\title{
As queimadas na região amazônica e o adoecimento respiratório
}

\author{
Ground-clearing fires in the Amazon and respiratory disease
}

Karen dos Santos Gonçalves ${ }^{1}$

Hermano Albuquerque de Castro ${ }^{2}$

Sandra de Souza Hacon ${ }^{1}$

${ }^{1}$ Departamento de Endemias Samuel Pessoa, Escola Nacional de Saúde Pública Sergio Arouca, Fundação Oswaldo Cruz. Rua Leopoldo Bulhões 1480/601, Manguinhos. 21041-210 Rio de Janeiro RJ.

karengoncalves@ensp.fiocruz.br ${ }^{2}$ Centro de Estudos de Saúde do Trabalhador e Ecologia

Humana, Escola Nacional de Saúde Pública Sergio Arouca, Fundação Oswaldo Cruz.
Abstract The intentional burning of forest biomass commonly known as "ground-clearing fires" is an age-old and widespread practice in the country and is seen as a major contributor to global emissions of greenhouse gases. However, global awareness of their potential impact is relatively recent. The occurrence of large ground-clearing fires in the Brazilian and international scenarios drew attention to the problem, but the measures taken to prevent and/or control the fires are still insufficient. In the Amazon region, with distinct geographical and environmental features from the rest of the country, with its historic process of land occupation, every year the ground-clearing fires expose larger portions of the population making them vulnerable to its effects. In this context, this non-systematic review presents the papers written over the past five years about the fires in the Brazilian Amazon and respiratory illness. The main objective is to provide information for managers and leaders on environmental issues about the problems related to biomass burning in the Amazon region.

Key words Ground-clearing fires, Respiratory disease, Amazon forest, Air pollution
Resumo A queima de biomassa florestal popularmente conhecida como "queimada" é uma prática recorrente e antiga no país e se caracteriza como um dos principais contribuintes mundiais para a emissão de gases de efeito estufa. Entretanto, a consciência global sobre seus possiveis impactos é relativamente recente. A ocorrência de grandes queimadas no cenário brasileiro e internacional despertou a atenção para o problema, mas as medidas tomadas para prevenir elou controlar os incêndios ainda são insuficientes. Na região amazônica, com circunstâncias geográficas e ambientais distintas do resto do país, aliadas a um processo histórico de ocupação do território, o uso do fogo expõe a cada ano, parcelas maiores da população tornando-as vulneráveis aos seus efeitos. Neste contexto, esta revisão não sistemática apresenta os trabalhos desenvolvidos nos últimos cinco anos sobre as queimadas na Amazônia Brasileira e o adoecimento respiratório. Tem como objetivo principal fornecer elementos para gestores e dirigentes ambientais sobre as questões que norteiam os problemas relacionados à queima de biomassa florestal na região amazônica.

Palavras-chave Queimada, Doença respiratória, Floresta amazônica, Poluição do ar 


\section{Introdução}

A cada ano, o fogo na Amazônia brasileira atinge uma área dez vezes o tamanho da Costa Rica ${ }^{1}$. Os incêndios florestais e o uso do fogo em sistemas agrícolas afetam o equilíbrio dos ecossistemas, a saúde humana, e consequentemente, o planeta.

Este equilíbrio é influenciado pelo acelerado crescimento populacional, mudanças no padrão de consumo e intensificação das atividades econômicas e tecnológicas, capazes de exercerem pressões sobre o nível de qualidade de vida das populações expostas.

Caracterizada entre os principais contribuintes mundiais para a emissão de gases de efeito estufa, a queima de biomassa é uma prática recorrente e antiga no país. Entretanto, a consciência global sobre seus possíveis impactos é relativamente recente.

Apesar de anos de estudos científicos sobre os impactos dos poluentes atmosféricos em áreas urbanas e a atenção da mídia em relação ao desmatamento e aos incêndios florestais, acidentais ou intencionais, os potenciais efeitos a saúde das populações tem sido pouco estudados pela comunidade científica ${ }^{2}$.

As grandes queimadas em Bornéu (1983 e 1997), Tailândia (1997), Indonésia (1997), Roraima (1997 - 1998), Mato Grosso (1998) e Pará (1998) despertaram a atenção para o problema, mas as medidas tomadas para prevenir e/ou controlar os incêndios ainda são insuficientes ${ }^{3}$.

Inserido neste contexto, esta revisão pretende fornecer elementos para gestores e dirigentes ambientais a fim de minimizar incertezas sobre as questões que norteiam os problemas relacionados à queima de biomassa, em especial na Amazônia Brasileira.

\section{Contexto Histórico dos Desmatamentos e Incêndios na Amazônia}

Existem inúmeros motivos para a degradação da floresta, dentre os principais estão o corte seletivo, incêndios (facilitados pelo corte) e atividades agropastoris. Os desmatamentos e as queimadas são duas das maiores questões ambientais enfrentadas pelo Brasil atualmente. Embora distintas, são práticas tradicionalmente associadas, pois em sequência à derrubada da vegetação, quase sempre há a queima do material vegetal.

Neste contexto, a floresta Amazônica permaneceu completamente intacta até o início da era "moderna" do desmatamento, com a inauguração da rodovia Transamazônica em 1970. Nos últimos anos a taxa de perda florestal tem sido dramática, cerca de $20 \%$ da floresta foi destruída, principalmente na região do "arco do desmatamento", que se estende do município de $\mathrm{Pa}$ ragominas, no Pará até Rio Branco, no Acre ${ }^{4}$.

A intensidade e o uso indiscriminado das queimadas transformaram-se em um grave problema ambiental para o país. Na medida em que se ampliavam as áreas de pecuária bovina, o emprego do fogo foi sendo incrementado. Os incentivos fiscais foram um forte condutor dos desmatamentos nas décadas de 70 e 80 e, desde 1991, vêm aumentando com o processo de desflorestamento em um ritmo variável, porém mais rápido ${ }^{5,6}$.

Levantamentos realizados no ano de 1998, na região do arco do desmatamento, encontraram apenas $25 \%$ das áreas desmatadas em propriedades iguais ou menores a 100 hectares. O que reflete o poder dos grandes empreendimentos na floresta ${ }^{1}$.

Nas florestas da Amazônia, o fogo se espalha como uma linha de chamas de movimento lento no sub-bosque. As bases de muitas árvores são queimadas à medida que o fogo se prolonga. Depois de várias queimadas, a área fica devastada a ponto de aparecer como desmatamento nas imagens de satélite ${ }^{3,7}$.

Um dos grandes exemplos de perda florestal ocorreu durante o fenômeno do El Niño, em 1997 e 1998. O incêndio de Roraima queimou uma área entre 11.394 e $13.928 \mathrm{Km}^{2}$ de floresta primária intacta ${ }^{8}$.

Do ponto de vista legal, o Código Florestal Brasileiro, instituído pela Lei 4.771 de 15 de setembro de 1965, classifica como bens de interesse público as florestas e as demais formas de vegetação, devido à sua utilidade e às terras que revestem. Esta Lei limita o exercício dos direitos de propriedade sobre a utilização e exploração de florestas, sendo as ações ou omissões contrárias às disposições deste Código consideradas como uso nocivo da propriedade ${ }^{9}$.

As áreas naturais protegidas são compostas ainda por unidades de conservação instituídas pelo poder público. As Unidades de Conservação, espaços territoriais sob regime especial de administração, aos quais se aplicam garantias adequadas de proteção, constituem o Sistema Nacional de Unidades de Conservação da Natureza (SNUC), instituído pela Lei 9.985/00.

Ferreira et al. ${ }^{10}$ observaram que mais de $90 \%$ do desmatamento realizado entre 2001 e 2003 ocorreu em áreas contíguas localizadas fora das áreas protegidas, reforçando a importância deste mecanismo de proteção. 
O uso do fogo em florestas e demais formas de vegetação é proibido. A exceção é o emprego do fogo em práticas agropastoris ou florestais quando justificado pelas peculiaridades locais ou regionais. O Decreto $\mathrm{n}^{\mathrm{o}} 2.661$, de 8 de julho de 1998 , regulamenta esta prática mediante o estabelecimento de normas de precaução. Especifica as situações nas quais o uso do fogo é proibido e as condições para a sua permissão. Trata, ainda, do ordenamento e da suspensão temporária do emprego do fogo, por meio do escalonamento regional do processo de queima controlada, com base nas condições atmosféricas e na demanda de autorizações de queima controlada, para manutenção dos níveis de fumaça produzidos. Por fim, cria, no âmbito do Instituto Brasileiro do Meio Ambiente e dos Recursos Naturais Renováveis - IBAMA, o Sistema Nacional de Prevenção e Combate a Incêndios Florestais PREVFO$\mathrm{GO}$, que tem por finalidade o desenvolvimento de programas destinados a ordenar, monitorar, prevenir e combater incêndios florestais; desenvolver e difundir técnicas de manejo controlado do fogo; capacitar recursos humanos para a difusão das respectivas técnicas; e conscientizar a população sobre os riscos do emprego inadequado do fogo 9 .

A Resolução Conama no. 3 de 1990 é a legislação federal que define os Padrões de Qualidade do Ar. Os limites correspondem a concentrações de poluentes atmosféricos que, quando ultrapassadas, podem afetar a saúde, a segurança e o bemestar da população, bem como ocasionar danos à flora e à fauna, aos materiais e ao meio ambiente em geral. Estabelecendo o monitoramento da qualidade do ar como uma atribuição dos estados, esta Resolução define, ainda, os Níveis de Qualidade do Ar para elaboração do Plano de Emergência para Episódios Críticos de Poluição do Ar, visando providências dos governos estaduais e municipais, com o objetivo de prevenir grave e iminente risco à saúde da população.

Mesmo com a definição de padrões por meio de concentrações médias de 1 hora, 8 horas, 24 horas ou anuais para diversos poluentes atmosféricos, a Resolução Conama no 3 , além de defasada em relação aos limites estipulados pela OMS, possui aplicação restrita em eventos de poluição aguda decorrentes de queimadas como as que ocorrem na região amazônica. Tanto a escolha dos parâmetros quanto a definição dos limites estipulados foram direcionados para a poluição atmosférica típica de centros urbanos ${ }^{9}$.

Em síntese, o desmatamento na região é decorrente de um conjunto de forças subjacentes, tais como: fragilidade institucional, políticas pú- blicas (econômicas e ambientais), agrotecnológicas e socioeconômicas (i.e.população, renda, demanda de alimentos), interesses governamentais que combinam entre si e agem sinergísticamente na manutenção desta prática no estado ${ }^{11}$.

Dessa forma, os desmatamentos e as queimadas não são um "problema ambiental" novo no Brasil. A consciência generalizada da dimensão dos danos socioambientais que estas práticas acarretam no país, tem crescido somente nas últimas décadas e merecem investigação e fiscalização.

\section{Queimadas e Emissão de Poluentes}

Queima de biomassa é um processo de combustão incompleta pelo qual o material reage rapidamente com o oxigênio do ar produzindo um intenso desprendimento de calor e luz. Para a sua efetividade são necessários três elementos básicos, a saber: combustível, comburente e temperatura de ignição. A combinação destes elementos produz uma reação em cadeia que tem, como um de seus produtos, o fogo 9 .

A equação química demonstra os principais produtos gerados, sendo eles, o dióxido de carbono $\left(\mathrm{CO}_{2}\right)$ e a água:

$\left[\mathrm{CH}_{2} \mathrm{O}\right]+\mathrm{O}_{2} \rightarrow \mathrm{CO}_{2}+\mathrm{H}_{2} \mathrm{O}$

$\mathrm{O}$ elemento $\left[\mathrm{CH}_{2} \mathrm{O}\right]$ representa a composição média da biomassa que se caracteriza por qualquer matéria, de origem vegetal ou animal, utilizada como fonte de energia.

São produzidas outras espécies químicas como o monóxido de carbono ( $\mathrm{CO}$ ), óxidos nitrosos $\left(\mathrm{NO}_{3}\right)$, hidrocarbonetos e partículas de aerossóis, os quais são incorporados na atmosfera sendo transportados e misturados ${ }^{12}$. Estes elementos sofrem reações fotoquímicas que auxiliam a formação de poluentes secundários como o ozônio $\left(\mathrm{O}_{3}\right)$, aldeídos e os peroxiacil nitratos, sendo estes mais tóxicos do que seus precursores ${ }^{13}$.

A evolução da combustão da matéria orgânica perpassa por quatro estágios: ignição, chamas, brasas e extinção. Diversos fatores ambientais, em especial os climáticos, influenciam a queima da matéria orgânica e suas emissões. As condições para a manutenção do fogo são controladas pelas características da biomassa, umidade relativa, temperatura, precipitação e velocidade dos ventos ${ }^{14}$.

De acordo com Arbex et al. ${ }^{2}$, cerca de $80 \%$ da queima de biomassa ocorre nos trópicos. Considerada a maior fonte de produção de gases tóxicos e de efeito estufa do planeta, influencia química e fisicamente a atmosfera produzindo espécies químicas que mudam significativamente o pH da água da chuva, afetando o balanço térmi- 
co pela interferência na quantidade de radiação solar refletida para o espaço.

Uma vez na troposfera, o transporte destes poluentes se dá de forma mais eficiente de acordo com as velocidades do fluxo do ar, deslocando-os para regiões distantes dos locais de emissão. Estes deslocamentos, ao longo do tempo, produzem alterações nos ciclos biogeoquímicos naturais e na dinâmica de nutrientes tanto das regiões emissoras quanto nas receptoras, transformando o problema antes local em global ${ }^{14}$.

\section{O Monitoramento Orbital de Queimadas}

O gerenciamento de queimadas engloba todas as atividades necessárias para a proteção e a manutenção dos recursos florestais pautandose na prevenção, controle, definição antecipada de risco e supressão de incêndios. Em contraste aos riscos geológicos e hidro-metereológicos, as queimadas podem ser previstas, controladas e, em muitos casos, evitadas ${ }^{15}$.

A extensão espacial da ocorrência de queima de biomassa em áreas tropicais torna o sensoriamento remoto por satélites a mais viável forma de controle e prevenção destes eventos ${ }^{14}$. Representa uma poderosa ferramenta para a compreensão da dinâmica do uso da terra e do desmatamento, assim como seus impactos ecológicos e sociais, além da redução dos custos de combate e atenuação dos danos ${ }^{16,17}$.

Segundo Guimarães ${ }^{18}$, a técnica de sensoriamento remoto pode ser definida como: conjunto de técnicas que permite a coleta de dados dos recursos naturais terrestres ou de seu meio ambiente, através de sensores a bordo de plataformas em altitude, que captam o fluxo de radiação eletromagnética emitida ou refletida pelos alvos, convertendo-os em um sinal passível de análise.

A obtenção de dados por esta técnica de monitoramento é relativamente recente, datando do início do século passado, e apresentou grandes avanços, em função dos conhecimentos adquiridos no período pós segunda guerra mundial. A partir da década de 70, o êxito dos primeiros programas de sensoriamento orbital resultou na utilização operacional e sistemática de dados pela sociedade civil, tendo vasta aplicabilidade pela comunidade científica. Dessa forma, o lançamento de satélites destinados, em especial, ao gerenciamento e monitoramento de recursos naturais, propiciou uma rápida evolução dos sensores 9 .

Segundo Phulpin et al. ${ }^{19}$ as imagens de satélite têm sido utilizadas para o monitoramento dos incêndios florestais tanto no aspecto global, es- tudos climáticos; como regional, para a avaliação de impactos das queimadas.

De acordo com Anderson et al. ${ }^{20}$ há duas linhas de pesquisa relacionadas à detecção das queimadas pela técnica de monitoramento: uma voltada à detecção dos focos de calor, importante para a definição da sazonalidade, frequência e variações anuais de queima; e a outra relacionada à espacialização das queimadas, pela quantificação da extensão das áreas afetadas por este evento.

No Brasil, o monitoramento de queimadas via sensoriamento remoto, iniciou em Julho de 1987, com a implementação do projeto SEQE Sensoriamento Remoto de Queimadas por Satélite, após vários acordos entre o Instituto Nacional de Pesquisas Espaciais (INPE) e o Instituto Brasileiro de Desenvolvimento Florestal (IBDF) ${ }^{10}$.

A detecção de focos de calor na região do cerrado e floresta tropical do Brasil foi desenvolvida por Pereira em 1981, com posterior implantação por Setzer e Pereira em 1991, da técnica de forma operacional no INPE. Para o monitoramento utilizaram o radiômetro AVRHH (Advanced Very High Resolution Radiometer) a bordo dos satélites NOAA (National Oceanic and Atmospheric Administration $)^{14}$.

O sistema operacional do INPE para detecção dos focos de calor envolve cinco etapas, a saber: recepção da imagem, seleção das queimadas na imagem, obtenção das coordenadas geográficas a medida que a imagem é analisada, elaboração e envio dos produtos ${ }^{21-23}$.

Desde então, o sistema de detecção de incêndios florestais vem sendo aperfeiçoado pelo INPE, com obtenção de focos de calor por meio de imagens termais dos satélites polares TERRA, AQUA, da série NOAA e dos satélites geoestacionários MSG e da série GOES. Em parceria com o Instituto Brasileiro do Meio Ambiente e dos Recursos Naturais Renováveis (IBAMA), e com a incorporação do IBDF, o monitoramento dos incêndios passou a ter ênfase na região Amazônica com a criação do Programa de Prevenção e Controle às Queimadas e aos Incêndios Florestais no Arco do Desflorestamento (PROARCO). A atenção para a região amazônica se deve às queimadas descontroladas de 1997 no sul da Amazônia e em março de 1998 em Roraima.

Segundo Souza ${ }^{9}$ dentre as inovações do sistema, destacam-se: mapas de risco de queima da vegetação observado, previsto e climático; banco de dados de queimadas datando de 1992; expansão do monitoramento das queimadas e produtos para vários países vizinhos ao Brasil; página de previsão de tempo da Amazônia; visualização 
do posicionamento dos satélites utilizados; informações sobre quantificação e dispersão de emissões de queimas; focos em Unidades de Conservação e áreas especiais; serviços de alertas para usuários cadastrados e; melhoria na resolução dos diversos mapas e produtos.

Foco de calor ou pixel quente é a expressão utilizada para interpretar o registro de calor captado da superfície do solo pelo satélite imageador. O sensor capta e registra qualquer temperatura acima de $47^{\circ} \mathrm{C}$ e a interpreta como sendo um foco ${ }^{24}$.

De acordo com Pereira ${ }^{25}$ existem três fontes de radiação envolvidas na detecção de incêndios:

1) Emissão pelo próprio incêndio: substâncias em combustão;

2) Emissão da reflexão da área em que ocorre o incêndio, juntamente com os resíduos da combustão;

3) Emissão e reflexão provenientes de outras fontes: solo exposto ou rochas nuas, influenciando no processo.

Sendo assim, um material em chamas emite energia na faixa-termal de $3,7 \mu \mathrm{m}$ a $4,1 \mu \mathrm{m}$ do espectro ótico. Para a detecção dos focos são utilizadas imagens que tenham esta faixa característica e nestas selecionam-se os elementos de imagem (pixels) com maior temperatura, saturando o sensor ${ }^{26}$.

\section{Os Efeitos na Saúde}

A Organização Mundial de Saúde (OMS) ${ }^{27} \mathrm{em}$ documento elaborado para eventos relacionados a incêndios florestais destaca a saúde como dependente de um ambiente saudável, evidenciando a necessidade em direcionar o problema das queimadas a um contexto global de mudanças.

Entretanto, apesar de toda a literatura disponível sobre a relação saúde e poluentes atmosféricos em centros urbanos, poucos são os estudos que abordam os efeitos à saúde das populações expostas à fumaça das queimadas, principalmente na região Amazônica.

Tal fato pode ser explicado, pois pesquisas relacionadas às queimadas devem considerar a influência de fatores exógenos abióticos que poderiam ter um ou mais efeitos diretos e indiretos com consequência aos ecossistemas, alterando o equilíbrio saúde/doença na região afetada. Ou seja, inúmeras variáveis que podem influenciar a ocorrência de agravos a saúde e separá-las para determinar o efeito isolado é bastante difícil, recomendando a existência de metodologias específicas para cada caso $^{27}$.

A clássica figura de pirâmide dos efeitos à saúde da OMS (Figura 1) ilustra os principais relacionados às queimadas e à parcela da população exposta. Em linhas gerais quanto mais sério o desfecho menor será a população atingida.

Dessa forma, a $\mathrm{OMS}^{28}$ preconiza quatro abordagens básicas para tratar dos riscos à saúde devido a emissões de queimadas, sendo elas:

. Caracterização da magnitude e da composição das emissões e suas transformações durante o transporte;

- Quantificação de concentrações resultantes de poluentes tóxicos na atmosfera de áreas povoadas;

- Avaliação de cenários prováveis da exposição para populações afetadas (ambientes fechados e abertos);

- Avaliação de riscos de saúde para as exposições humanas.

\section{Os Estudos Nacionais}

Tanto nos países desenvolvidos como em desenvolvimento as doenças do aparelho respiratório representam uma elevada proporção de morbidade e considera-se que $60 \%$ das doenças respiratórias estejam relacionadas aos poluentes ambientais $^{29}$.

A vulnerabilidade biológica de crianças e idosos em relação à poluição atmosférica decorre de peculiaridades fisiológicas. Na criança, fatores como maior velocidade de crescimento, maior área de perda de calor por unidade de peso, elevadas taxas de metabolismo em repouso e consumo de oxigênio, possibilitam que os agentes químicos presentes na atmosfera acessem suas vias respiratórias de forma mais rápida em comparação aos adultos. Nos idosos, fatores relacionados à baixa imunidade e à redução da função

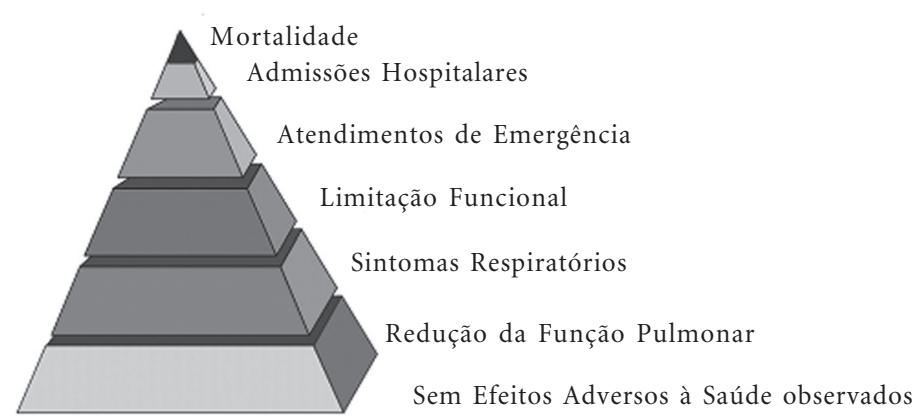

Figura 1. Pirâmide dos Efeitos à Saúde.

Fonte: Adaptado de $\mathrm{WHO}^{29}$ 
ciliar contribuem para aumentar a vulnerabilidade para o adoecimento respiratório relacionados aos poluentes do ar.

A seguir são apresentados os estudos desenvolvidos no Brasil no período de 2007 a 2011 relacionados aos eventos de queima de biomassa e incêndios florestais e os efeitos à saúde.

$\mathrm{Na}$ cidade de Rio Branco, capital do Acre, Mascarenhas et al. ${ }^{30}$ desenvolveram um estudo ecológico em função da elevada concentração de fumaça na cidade no mês de Setembro de 2005. Foram avaliados a relação entre a concentração diária de $\mathrm{PM}_{2,5}$ e o número de atendimentos diários de emergência por doença respiratória. $\mathrm{Ob}$ servou-se que a concentração de $\mathrm{PM}_{2,5}$ ultrapassou o limite de qualidade do ar durante 23 dias. O número de atendimentos em crianças menores do que 10 anos aumentou e observou-se uma correlação positiva entre a concentração do material particulado e atendimentos de asma.

Souza9 ${ }^{9}$ desenvolveu um estudo ecológico também no município de Rio Branco, Acre para o período de 2000 a 2006 relacionando o aumento dos focos de calor captados pelos sensores AVHRR/NOAA com as internações hospitalares em crianças menores de quatro anos e idosos com idade superior a 65 anos. Observou-se uma relação entre o aumento do número de internações em comparação à quantidade de focos de calor observados.

Em estudo transversal realizado no município de Tangará da Serra, Mato Grosso, região dentro do arco de desmatamento, Rosa et al. ${ }^{31}$ analisaram as internações hospitalares por doenças respiratórias em menores de 15 anos de idade em uma área com elevados níveis de poluição ambiental, no período de 2000 a 2005. Observou-se que as taxas de internação por doenças respiratórias nesse grupo etário foram de 70/ 1.000 crianças. No período de seca (Maio a Outubro) houve um aumento de mais de $10 \%$ nas internações em comparação ao período de chuva (Novembro a Abril). As principais causas de internação foram: pneumonia $(90,7 \%)$ e insuficiência respiratória $(8,5 \%)$. Em menores de 5 anos de idade, as internações por pneumonia foram quatro vezes o esperado para o município. Os menores de 12 anos foram mais frequentemente internados, com incremento médio de 32,4 internações por 1000 crianças a cada ano.

Em pesquisa desenvolvida por Castro et al. ${ }^{32}$, os autores analisaram a tendência da mortalidade por doenças respiratórias em idosos no estado de Rondônia, para o período de 1998 a 2005, época de intensificação das queimadas na região. Utilizaram como variáveis a taxa de mortalidade por Doenças do Aparelho Respiratório (DAR) e a Doença Pulmonar Obstrutiva Crônica (DPOC) e o número de focos de calor. Os resultados encontrados explicaram de $50 \%$ até $80 \%$ das mortes por DAR em idosos na região, sendo estas possivelmente relacionadas às queimadas. Consideraram, contudo, as complexidades de determinação de óbitos por doenças respiratórias neste grupo etário, em função de serem portadores de patologias crônicas e debilidade imunológica.

Ignotti et al. ${ }^{33}$ realizaram um estudo ecológico com objetivo de observar a associação das hospitalizações por doenças respiratórias em todas as idades e internações provenientes de complicações do parto em relação ao indicador de exposição ambiental apresentado como porcentagem anual de horas (AH\%) de $\mathrm{PM}_{2,5}$ em todas as microrregiões da Amazônia Brasileira. Observou-se maior associação do indicador de exposição com as internações entre os idosos $(\beta=$ $0,10)$. Para cada ponto percentual de aumento no indicador de exposição, houve aumento de $10 \%$ na taxa de hospitalização para este grupo, $8 \%$ em internações de crianças, e 5\% para a faixa etária intermediária, admitindo ajuste por IDH e número médio de hemogramas. Contudo, não foi encontrada associação entre AH\% e a taxa de hospitalização por parto.

O estudo ecológico de série temporal realizado por Carmo et al. ${ }^{34}$ no município de Alta Floresta, Mato Grosso do Sul objetivou estabelecer a relação entre os efeitos a curto prazo da exposição ao $\mathrm{PM}_{2,5}$ e os atendimentos ambulatoriais por doenças respiratórias em crianças e idosos no município. $\mathrm{O}$ autor encontrou um incremento de $10 \mu \mathrm{g} / \mathrm{m} 3$ nos níveis de exposição ao material particulado esteve associado a aumentos de 2,9 e 2,6\% nos atendimentos ambulatoriais por doenças respiratórias de crianças no $6^{\circ}$ e $7^{\circ}$ dias subsequentes à exposição. Não foram encontradas associações significativas nos atendimentos de idosos.

Rodrigues et al. ${ }^{35}$ descreveram a distribuição espacial da taxa padronizada de internação por asma em idosos na Amazônia Brasileira. Observou que as internações apresentavam tendência decrescente ao longo do período estudado, bem como importante variação sazonal com predominância deste evento durante o período seco. Ressaltou também que ao comparar o período seco ao período das chuvas, as internações aumentavam em até três vezes, com taxas mais elevadas em Rondônia (5,8\%o) e Mato Grosso (3,3\%o).

$\mathrm{O}$ estudo desenvolvido por Silva ${ }^{36}$ em Cuiabá, Mato Grosso teve como objetivo investigar os efeitos da exposição ao material particulado originário de queimadas sobre a saúde de gru- 
pos populacionais sensíveis. Concluiu que as emissões de $\mathrm{PM}_{2,5}$ estão relacionadas à maior prevalência de internações por doenças respiratórias em crianças nos municípios do estado de Mato Grosso. Os níveis de $\mathrm{PM}_{2,5}$ também foram associados à ocorrência diária de internações por doenças respiratórias em crianças em Cuiabá e à ocorrência de BPN em municípios selecionados do estado de Mato Grosso.

$\mathrm{Na}$ pesquisa desenvolvida por Andrade ${ }^{37}$ no município de Manaus, Amazonas a relação entre exposição ao $\mathrm{PM}_{2,5}$ e a ocorrência de internações hospitalares por doenças respiratórias não se tornou tão evidente. $\mathrm{O}$ autor observou que as internações hospitalares em Manaus estão mais associadas às condições meteorológicas. Entre- tanto, ressaltou que a região de Manaus apresenta baixas concentrações do material particulado em relação à porção sul da região amazônica o que poderia influenciar em seus achados.

Oliveira $^{38}$ realizou uma avaliação de risco da exposição ao $\mathrm{PM}_{2,5}$ em crianças de 6 a 14 anos residentes no município de Tangará da Serra, Mato Grosso no ano de 2008. Observou que elas incorporaram uma dose potencial média de $\mathrm{PM}_{2,5}$ de 2,05 ìg/kg.dia (IC 95\%: 1,91-2,18) no cenário da seca e 0,32 ìg/kg.dia (IC 95\%: 0,31-0,34) no cenário de chuva. Concluiu que durante a estação da seca, a exposição aos níveis de $\mathrm{PM}_{2,5}$ representou risco toxicológico para crianças entre 6 a 14 anos residentes em áreas de queima de biomassa (Quadro 1).

Quadro 1. Principais estudos nacionais.

\begin{tabular}{|c|c|c|c|c|}
\hline Referências & População & Delineamento & Resultados & Desfecho \\
\hline \multirow{2}{*}{$\begin{array}{l}\text { Mascarenhas } \\
\text { et al. }{ }^{30}\end{array}$} & \multirow{2}{*}{$\begin{array}{l}\text { Todas as idades. } \\
\text { Rio Branco, Acre }\end{array}$} & \multirow{2}{*}{$\begin{array}{l}\text { Ecológico de } \\
\text { série temporal }\end{array}$} & $\begin{array}{l}\text { Maior incidência de DR em } \\
\text { crianças < } 10 \text { anos; }\end{array}$ & \multirow{2}{*}{$\begin{array}{l}\text { Atendimentos de emergência por } \\
\text { doenças respiratórias e asma }\end{array}$} \\
\hline & & & $\begin{array}{l}\text { Correlação positiva entre a } \\
\text { concentração de PM 2,5 e } \\
\text { atendimentos por asma. }\end{array}$ & \\
\hline Souza $^{9}$ & $\begin{array}{l}\text { Crianças }<4 \text { a e } \\
\text { Idosos }+ \text { de } 65 a \text {. } \\
\text { Rio Branco, Acre }\end{array}$ & $\begin{array}{l}\text { Ecológico de } \\
\text { série temporal }\end{array}$ & $\begin{array}{l}\text { Relação entre o aumento dos } \\
\text { focos de queima com o aumento } \\
\text { das internações hospitalares por } \\
\text { DAR }\end{array}$ & Hospitalizações por DAR \\
\hline Rosa et al. ${ }^{31}$ & $\begin{array}{l}\text { Menores de } 15 \\
\text { anos. Tangará da } \\
\text { Serra, Mato } \\
\text { Grosso }\end{array}$ & Transversal & $\begin{array}{l}\text { Aumento das internações } \\
\text { hospitalares por doenças } \\
\text { respiratórias no período das } \\
\text { queimadas (seca) }\end{array}$ & $\begin{array}{l}\text { Hospitalizações por DAR, pneumonia } \\
\text { e Insuficiência Respiratória }\end{array}$ \\
\hline $\begin{array}{l}\text { Saldanha } \\
\text { et al. }{ }^{39}\end{array}$ & $\begin{array}{l}\text { Crianças asmáticas } \\
<5 \text { a. Cuiabá, Mato } \\
\text { Grosso }\end{array}$ & $\begin{array}{l}\text { Ecológico de } \\
\text { série temporal }\end{array}$ & $\begin{array}{l}\text { Relação entre os atendimentos } \\
\text { por asma e focos de calor }\end{array}$ & $\begin{array}{l}\text { Aumento da proporção de } \\
\text { atendimentos por asma em crianças } \\
\text { menores de } 5 \text { anos }\end{array}$ \\
\hline $\begin{array}{l}\text { Castro } \\
\text { et al. }{ }^{32}\end{array}$ & $\begin{array}{l}\text { Idosos acima de } \\
65 \text { anos. } \\
\text { Rondônia }\end{array}$ & $\begin{array}{l}\text { Ecológico de } \\
\text { série temporal }\end{array}$ & $\begin{array}{l}\text { Relação entre taxa de } \\
\text { mortalidade por DAR e DPOC } \\
\text { e o número de focos de calor. }\end{array}$ & $\begin{array}{l}\text { Tendência crescente dos óbitos por } \\
\text { DAR e DPOC }\end{array}$ \\
\hline $\begin{array}{l}\text { Ignotti } \\
\text { et al. }{ }^{33}\end{array}$ & $\begin{array}{l}\text { Todas as idades. } \\
\text { Microrregiões da } \\
\text { Amazônia } \\
\text { Brasileira }\end{array}$ & $\begin{array}{l}\text { Ecológico de } \\
\text { série temporal }\end{array}$ & $\begin{array}{l}\text { Relação entre } \mathrm{PM}_{2,5} \text { taxa de } \\
\text { hospitalizações por doenças } \\
\text { respiratórias e complicações no } \\
\text { parto }\end{array}$ & $\begin{array}{l}\text { Associação com doenças respiratórias } \\
\text { dentre os grupos mais vulneráveis }\end{array}$ \\
\hline $\begin{array}{l}\text { Carmo } \\
\text { et } \mathrm{al}^{34}\end{array}$ & $\begin{array}{l}\text { Todas as idades. } \\
\text { Alta Floresta, } \\
\text { Mato Grosso }\end{array}$ & $\begin{array}{l}\text { Ecológico de } \\
\text { série temporal }\end{array}$ & $\begin{array}{l}\text { Relação entre PM2.5 e } \\
\text { atendimento ambulatorial por } \\
\text { doenças respiratórias em } \\
\text { crianças e idosos. }\end{array}$ & $\begin{array}{l}\text { Um incremento de } 10 \mu \mathrm{g} / \mathrm{m} 3 \text { nos } \\
\text { níveis de exposição ao material } \\
\text { particulado esteve associado a } \\
\text { aumentos de } 2,9 \text { e } 2,6 \% \text { nos } \\
\text { atendimentos ambulatoriais por } \\
\text { doenças respiratórias de crianças }\end{array}$ \\
\hline
\end{tabular}




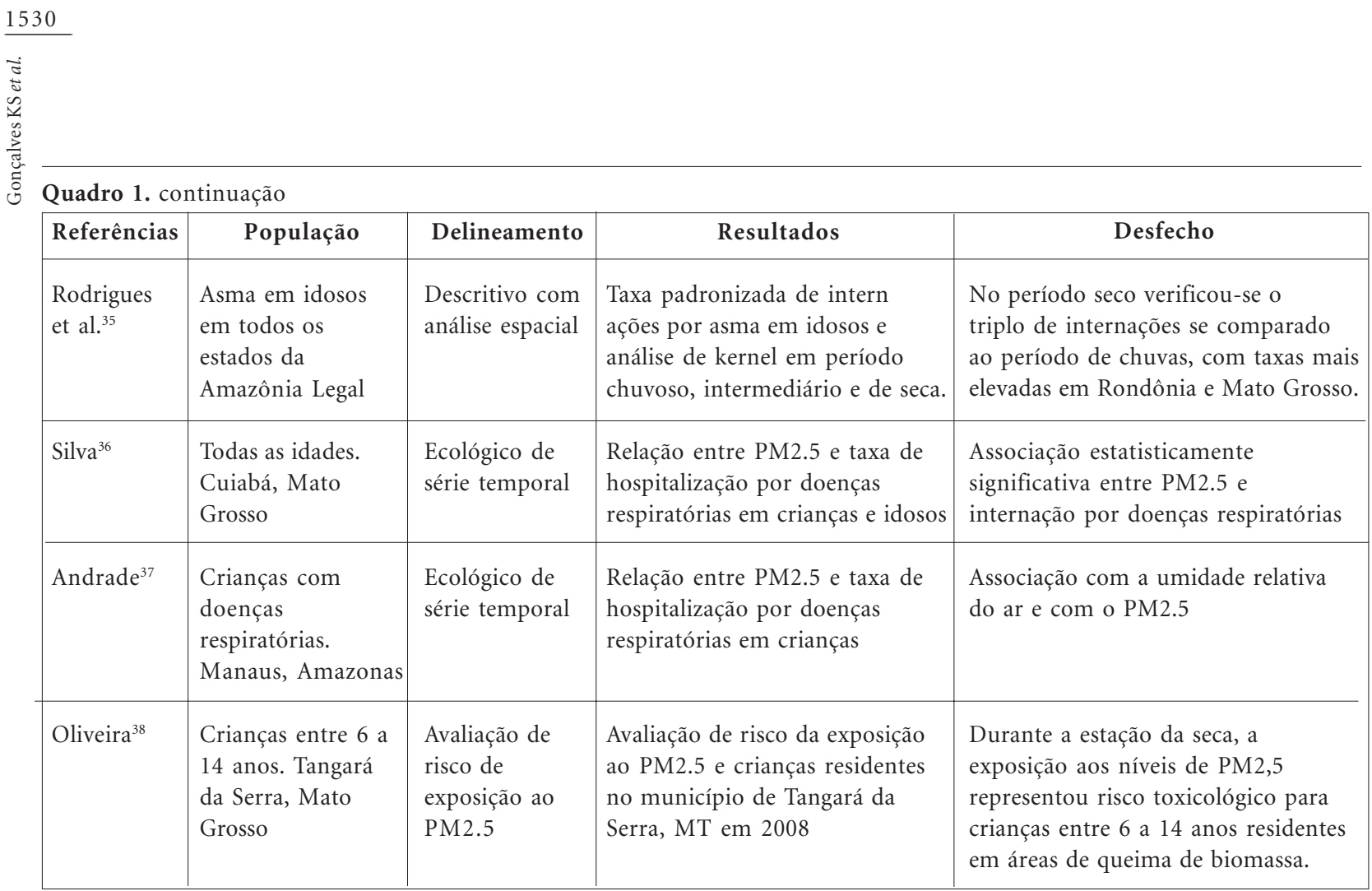

\section{Consideração final}

É de extrema importância o conhecimento sobre os impactos das queimadas sobre a saúde humana. As informações devem ser organizadas, repassadas e discutidas não somente entre as autoridades locais, mas principalmente junto às equipes multidisciplinares, permitindo o monitoramento e a tomada de decisão frente aos problemas ambientais e de Saúde Pública levantados. A instituição de medidas para promoção da saúde, acompanhamento dos fatores de risco, identificação precoce de casos e definições de estratégias, pode possibilitar a redução da vulnerabilidade dos sistemas socioambientais, capacidade de organização dos serviços e melhor aproveitamento dos recursos disponíveis ${ }^{28,40,41}$.

\section{Colaboradores}

KS Gonçalves, HA de Castro e SS Hacon participaram igualmente de todas as etapas da elaboração do artigo. 


\section{Referências}

1. Nepstad DC, Moreira AG, Alencar AA. Floresta em Chamas: Origens, Impactos e Prevenção do Fogo na Amazônia. In: Ipam. Programa Piloto para Proteção das Florestas Tropicais do Brasil. Ipam: Brasília; 1999.

2. Arbex MA, Cançado JED, Pereira LAA, Braga ALF, Saldiva PHN. Queima de biomassa e efitos sobre a saúde. J Bras. Pneumol. 2004; 30(2):158-175.

3. Cochrane MA. O grande incêndio de Roraima. Ciência Hoje 2000; 27:26-43.

4. Fearnside PM. Desmatamento na Amazônia brasileira: história, índices e conseqüências. Megadiversidade 2005; 1(1):113-123.

5. Alencar A, Moreira A, Nepstad D. Floresta em Chamas: Origens, Impactos e Prevenção do Fogo na Amazônia. Brasília/DF: Ipam; 2005.

6. Mahar DJ. Frontier development policy in Brazil: a study of Amazonia. Nova York: Praeger; 1979.

7. Nepstad D, Capobianco JP, Barros AC, Carvalho G, Moutinho P, Lopes U, Lefebvre P. Avança Brasil: os custos ambientais para a Amazônia. Belém: Gráfica e Editora Alves; 2000.

8. Barbosa RI, Fearnside PM. Incêndios na Amazônia Brasileira: estimativa de emissão de gases do efeito estufa pela queima de diferentes ecossistemas de Roraima na passagem do evento "El Niño" (1997/ 98). Acta Amazônica 1999; 29(4):513-534.

9. Souza LSN. Análise de Impactos das Queimadas sobre a Saúde Humana: Um estudo de caso do Município de Rio Branco, Acre [dissertação]. Rio de Janeiro: ENSP; 2008.

10. Ferreira LV, Venticinque E, Almeida S. O desmatamento na Amazônia e a importância das áreas protegidas. Estud. av. 2004; 19(53):157-166.

11. Brasil. Ministério do Meio Ambiente (MMA). Programa Piloto para a proteção das florestas tropicais do Brasil - PPG7. Diagnóstico dos principais vetores, dinâmica e tendências do desmatamento no estado de Rondônia. Gabriel de Lima Ferreira - Produto 1 - Contrato no 2009/00325- MMA/PNUD. Porto Velho, Rondônia: MMA; 2009.

12. Andreae MO. Biomass burning: It is history, use and distribution and its impact on environmental quality and global climate. In: Levine JS, editor. Global Biomass Burning: Atmospheric, Climatic and Biospheric Implications. Cambridge: MIT Press; 1991. p. 3-21.

13. Ribeiro H. Fossil fuel energy impacts on health. In: Unesco. Encyclopedia of Life Support Systems. Paris: Unesco; 2001.

14. Freitas SR, Longo KM, Dias MAFS, Dias PLS. Emissões de queimadas em ecossistemas da América do Sul. Estud. av. 2005; 19(53):167-185.

15. Goldammer JG. Early warning systems for the prediction of an appropriate Response to wildfires and related environmental hazards. In: Health Guidelines for Vegetation Fire Events; Lima, Peru, 1998 Oct 6-9. Freigurg: Freiburg University; 1998.

16. França DA, Ferreira NJ. Considerações sobre o uso de satélites na detecção e avaliação de queimadas. In: XII Simpósio Brasileiro de Sensoriamento Remoto. Goiânia, Brasil, 2005 abr 16-21. São José dos Campos: INPE; 2005. p. 3017-3023.
17. Batista A. Detecção de incêndios florestais por satélites. Revista Floresta 2004; 34(2):237-241.

18. Guimarães RJPS. Seleção das bandas do sensor Modis Airbone Simulator (MAS) na discriminação de queimadas [dissertação]. São José dos Campos: INPE; 2000.

19. Phulpin T, Lavenu F, Bellan MF, Mougenot B, Blasco F. Using SPOT-4 HRVIR and VEGETATION sensors to assess impact of tropical forest fires in Roraima, Brazil. International Journal of Remote Sensing 2002; 23(10):1943-1966.

20. Anderson LO, Aragão LEOC, Lima A, Shimabukuro E. Detecção de cicatrizes de áreas queimadas baseada no modelo linear de mistura espectral e imagens índice de vegetação utilizando dados multitemporais do sensor MODIS/TERRA no estado do Mato Grosso, Amazônia brasileira. Acta Amaz 2005; 35(4):445-456.

21. Setzer A, Yoshida MC. Detecção de Queimadas nas Imagens do Satélite Geoestacionário GOES-12 [relatório técnico versão 3.4]. São José dos Campos: DAS, CPTEC, INPE; 2004. [acessado 2008 nov 10]. Disponível em: http://sigma.cptec.inpe.br/queimadas/v_ anterior/documentos/relat_goes.htm

22. Pereira G, Moraes EC, Arai E, Oliveira LGL. Comparação das áreas de queimada obtidas através de dados de campo e de dados do sensor CCD/CBERS 2. Anais XIII Simpósio Brasileiro de Sensoriamento Remoto; 2007 abr 21-26; Florianópolis, Brasil. São José dos Campos: INPE; 2007. p. 1017-1022.

23. Pinto MLA. Relação empírica da visibilidade com profundidade óptica, concentração de aerossóis e focos de queimadas em Alta Floresta e Cuiabá, em 1993 e 1994 [dissertação]. São José dos Campos (SP): INPE; 2001.

24. Instituto Brasileiro do Meio Ambiente e dos Recursos Naturais Renováveis (IBAMA). [página na Internet]. [acesso 2008 nov 10]. Disponível em: http://www.ibama.gov.br/

25. Pereira MC. Detecção, monitoramento e analise de alguns efeitos ambientais de queimadas na Amazônia através da utilização de imagens dos satélites NOAA e Landsat, $e$ dados de aeronave [dissertação]. São José dos Campos (SP): INPE; 1987.

26. Instituto Nacional de Pesquisas Espaciais (INPE). [página na Internet]. [acesso 2008 nov 10]. Disponível em: http://www.inpe.br/

27. Ribeiro H, Assunção JV. Efeitos das queimadas na saúde humana. Estud. av. 2002; 16(44):125-148.

28. Organização Mundial de Saúde (OMS). Indicadores para o estabelecimento de políticas e a tomada de decisão em saúde ambiental [mimeo]. Genebra: OMS; 1998.

29. World Health Organization (WHO). Health Guidelines for Vegetation Fire Events. Geneva: WHO; 1999.

30. Mascarenhas MDM, Vieira LC, Lanzieri TM, Leal APPR, Duarte AF, Hatch AL. Poluição atmosférica devido a queima de biomassa florestal e atendimentos de emergência por doença respiratória em Rio Branco, Brasil - Setembro, 2005. J Bras Pneumol 2008; 34(1):42-46.

31. Rosa AM, Ignotti E, Hacon SS, Castro HA. Análise das internações por doenças respiratórias em Tangará da Serra - Amazônia Brasileira. J Bras Pneumol 2008; 34(8):575-582. 
32. Castro HA, Gonçalves KS, Hacon SS. Tendência da mortalidade por doenças respiratórias em idosos e as queimadas no estado de Rondônia/Brasil - período entre 1998 e 2005. Cien Saude Colet 2009; 14(6): 2083-2090.

33. Ignotti E, Valente JG, Longo KM, Freitas SR, Hacon SS, Artaxo PN. Impact on human health of particulate matter emitted from burnings in the Brazilian Amazon region. Rev Saude Publica 2010; 44(1):121-130.

34. Carmo CN, Hacon S, Longo KM, Freitas S, Ignotti E, Ponce de Leon A, Artaxo P. Associação entre material particulado de queimadas e doenças respiratórias na região sul da Amazônia brasileira. Rev Panam Salud Publica 2010; 27(1):10-16.

35. Rodrigues PCO, Ignotti E; Rosa AM; Hacon SS. Spatial distribution of asthma-related hospitalizations of the elderly in the Brazilian Amazon. Rev Bras Epidemiol 2010; 13(3):1-10.

36. Silva AMC. Quantificação dos efeitos na saúde da exposição à queima de biomassa: uma contribuição ao entendimento dos efeitos da exposição ao material particulado $\left(P M_{2,5}\right)$ em grupos populacionais sensiveis na Amazônia Legal [tese]. Fiocruz: Rio de Janeiro; 2010.

37. Andrade VSF. Estudo da associação entre material particulado emitido em queimadas e doenças respiratórias no município de Manaus, AM [dissertação]. INPA: Manaus; 2011

38. Oliveira BFA. Avaliação do risco a saúde infantil relativa à exposição ao $P M_{2,5}$ proveniente da queima de biomassa no município de Tangará da Serra - MT. 2011 [dissertação]. Fiocruz: Rio de Janeiro; 2010.

39. Saldanha CT, Botelho C. Queimadas e suas influências em crianças asmáticas menores de cinco anos atendidas em um hospital público. Rev. bras. alerg. imunopatol. 2008; 31(3):108-112.

40. Ministério da Saúde. Secretaria de Vigilância à Saúde. Vigilância em saúde ambiental relacionada à qualidade do ar - VIGIAR. Brasília: MS; 2006.

41. Organização das Nações Unidas para a Educação, a Ciência e a Cultura (Unesco). Documento Técnico contendo proposta de metodologia para implantação de unidades sentinelas para a vigilância em saúde ambiental relacionada à qualidade do ar. Brasília: Unesco; 2006.

Artigo apresentado em 01/04/2012

Aprovado em 19/04/2012

Versão final apresentada em 04/05/2012 